\title{
Los museos interactivos como mediadores pedagógicos.*
}

\section{Guillermo Orozco Gómez ${ }^{11}$}

\section{Resumen}

En este ensayo se propone una fundamentación pedagógica para sustentar proyectos educativos en museos interactivos de ciencia y tecnología. Se reconoce que los museos contemporáneos son asumidos como de la "cuarta generación" por tener un proyecto específico para propiciar múltiples aprendizajes en sus usuarios. Este proyecto, además de conferir a los museos su estatuto actual de escenarios interactivos, requiere de la concurrencia de varias disciplinas entre las que destacan la comunicación y la educación que, junto a la museología, permiten una convergencia conceptual-estratégica en función de ofrecer a los usuarios del museo una experiencia educativa integral y lúdica en la que desarrollen conocimientos y saberes, y competencias comunicativas. La fundamentación pedagógica que se delinea en estas páginas se inscribe dentro de un paradigma de "descubrimiento", no de imitación, en el que a través de la exploración interactiva, corporal y virtual, los mismos usuarios van ejercitándose y descubriéndose a sí mismos como constructores de conocimiento. $Y$ el tipo de museo que se busca conformar se propone aquí como un escenario propicio para el trabajo profesional, sobre todo, de educadores y comunicadores.

\section{Palabras clave}

Museos, mediación pedagógica, interactividad, pedagogía lúdica, comunicación, aprendizaje no formal, paradigma del descubrimiento.

\section{Summary}

In this essay, a pedagogic platform is proposed in order to ground educational projects for interactive, science museums. It is recognized that contemporary museums from the so called "fourth generation" are developed precisely this way because of their specific mission to promote and facilitate multiple learning by their visitors. This mission, besides giving a special academic status to the museums, is intended to facilitate the convergence of several disciplines, especially comunication and education. Museology is not sufficient by itself, since the main general objective in these museums is to offer visitors an integral, educational, ludic experience. An experience in which visitors are able to develop concepts and learn skills, as well as abilities and communication competencies, while they are entertained. The pedagogic platform discussed in these pages draws from a "discovery" paradigm, instead of an "imitation" one and focusses on interactive exploration, both physical and virtual, throughout which the visitors themselves go through a process of knowledge construction. In order to accomplish this proposal, it is necessary to invent a multidisciplinary team of professionals.

\footnotetext{
- Este texto ha sido elaborado a partir de los avances de un proyecto mayor en realización que el autor desarrolla para el museo interactivo Trompo Mágico de la ciudad de Guadalajara, México. Fue recibido el 29 de marzo de 2004 y arbitrado el 21 de abril de 2004.

11 Doctor en educación, profesor titular de tiempo completo en el Departamento de Estudios de la Comunicación Social de la Universidad de Guadalajara. E-mail: gorozco@udgserv.cencar.udg.mx 


\section{Key words}

Museums, pedagogic mediation, interactivity, ludic pedagogy, communication, informal learning, discovery paradigm.

Tanto entre comunicadores como entre educadores y especialistas en museología existe un creciente consenso de que los museos contemporáneos ya no deben de concebirse y organizarse como lugares para la contemplación u observación pasiva de sus visitantes, sino como escenarios para su desarrollo educativo a través de situaciones comunicativas que propicien una interacción lúdica, una exploración creativa y una experimentación dirigida que a su vez posibiliten un involucramiento intelectual, físico y emocional de sus usuarios.

Entender al museo de esta manera, no sólo implica un cambio de 180 grados en su concepción, sino enfrentar una serie de desafíos diferentes y hasta inéditos, arquitectónicos, estéticos, comunicativos y, sobre todo, educativos que permitan hacer realidad estas características que perfilan a los museos actualmente.

Concebir a un museo como un escenario interactivo, apto para la exploración y el descubrimiento y finalmente para el crecimiento intelectual, cultural y humano de sus usuarios supone, antes que otra cosa, diseñar un proyecto educativo integral, que haga posible convertir al propio museo en un escenario innovador de aprendizaje creativo y significativo. Supone delinear un diseño que sustente pedagógicamente y a la vez dote de un sentido educativo a los diferentes objetos, imágenes, tecnologías, instrumentos, espacios, módulos y exposiciones que lo constituyen.

En este contexto, mi objetivo en estas páginas es delinear una propuesta de fundamentación pedagógica para los museos interactivos contemporáneos, destacándolos especialmente como escenarios para la construcción de aprendizajes dentro de un paradigma de exploración y descubrimiento, no de imitación y memorización. Estoy convencido de que son los museos interactivos lugares potencialmente ricos para contribuir al desarrollo integral de los niños y jóvenes y para su sensibilización ética y artística al mundo de la ciencia, la tecnología y la cultura.

Hay un creciente interés entre educadores por consolidar a los museos interactivos, especialmente aquellos responsables de ciencia y tecnología (Paris, 2002) como escenarios de aprendizaje no formal, para lo cual se discuten propuestas diversas que posibiliten que el sentido educativo de los museos sea visible y, por tanto, evidente en todo el dispositivo museográfico. Lo educativo, entonces, es lo que otorga a los museos de la cuarta generación, además de un sentido global, una racionalidad intrínseca, desde la cual se estructuren también otros apoyos y otras vinculaciones dentro y fuera con instituciones varias y con experiencias múltiples; todo en beneficio de consolidar su misión trascendental en el desarrollo humano de sus usuarios.

Las condiciones que debe reunir un museo de la cuarta generación son: interactividad, alta tecnología y proyecto educativo.

La experiencia reciente en diversos países va mostrando cómo los mismos usuarios de los museos contemporáneos (niños, jóvenes y adultos por igual) demandan a estos una oferta versátil que les permita usar su exploración del museo para tener a la vez que una 
oportunidad inspiradora de conocimiento, una posibilidad de diversión y vivencia del tiempo libre de un alto nivel o de un orden distinto y una experiencia en la que puedan desatar su creatividad a partir de los diversos estímulos con los que interactúen.

Los usuarios de los museos requieren de un acoplamiento particular al conjunto de experiencias que les depara el recinto museográfico. Independientemente de sus legítimas demandas y expectativas, el usuario debe pasar por un proceso específico de "inducción" que le permita sacar el mayor provecho posible de su visita. Como usuario de un museo de la cuarta generación no se nace, hay que hacerse, y en gran medida el propio museo tiene que asumir la responsabilidad educativa en esa "hechura".

Satisfacer éstas y otras demandas exige necesariamente tener un eje o ejes articuladores bien definidos y anclados, tanto en la realidad de los usuarios (perfil, condicionantes y expectativas cognoscitivas y culturales), como en la realidad del conocimiento científico y el avance de la tecnología, así como en los mismos fines educativos del museo para, desde su intersección, sustentar hipótesis de investigación y trabajo que hagan realidad su misión general.

Cada vez más, a partir de la fundación del museo Exploratorium, de San Francisco, en 1969 -que los especialistas coinciden en señalar como el primer ejemplo de museo concebido y diseñado desde su origen totalmente interactivo-, los museos infantiles y los museos científicos anteriores han reconceptuado su propia "mediación pedagógica" al constatar que su potencial educativo y lúdico se ve multiplicado cuando no sólo criterios estéticos o científicos o de valor intrínseco de los objetos que exponen en sus colecciones y en sus salas se cumplen, sino justamente cuando logran rearticularlos con un proyecto educativo preciso y complejo.

Para contribuir a lograr un aprendizaje creativo en sus usuarios, un aprendizaje que una vez iniciado siempre se renueve, es necesario definir y distinguir una serie de puntos sobre los cuales tejer el proyecto educativo de un museo.

Siendo coherentes con una perspectiva contemporánea museológica y educativa, a la vez innovadora y crítica, se parte de los usuarios mismos que son la razón de ser de un museo interactivo para continuar con sus interacciones y procesos de aprendizaje, y concluir con el museo en sí mismo y su oferta museográfica.

Con esta secuencia se busca deliberadamente invertir el orden tradicional de los factores que componen el proceso educativo, sabiendo que esta inversión de orden sí altera el producto, ya que ha quedado ampliamente mostrado en la literatura sobre educación que un auténtico proyecto educativo si bien se concibe de manera integral, siempre tiene un punto de partida: las personas, los educandos, que en el caso de los museos interactivos contemporáneos son niños y jóvenes, principalmente (Next Generation Forum, 1999). Y hay que enfatizarlo, no es ni el contenido, ni la institución el, o los puntos de partida, como tradicionalmente se acostumbra en otras situaciones y esfuerzos de educación. En la perspectiva de un aprendizaje por descubrimiento, el contenido, si bien se considera fundamental, se asume como un referente y como un pretexto para lograr ciertos fines. De manera similar, un museo, como institución, se asume como un facilitador responsable y comprometido con su entorno y con el desarrollo humano de sus usuarios. Y la tecnología y mobiliario son también desplegados siempre como medios para los fines sustantivos propuestos. 


\section{Los usuarios del museo}

Como se han venido nombrando en estas páginas, los visitantes son concebidos como usuarios. Esto porque un museo interactivo no los interpela como consumidores pasivos del espectáculo o de la función montada en sus salas, sino como individuos y colectivos activos e interactuantes con el dispositivo museográfico. Son los usuarios los que usan los diferentes constructos y módulos para producir resultados, algunos esperados y otros no esperados, producto de su creatividad e iniciativa.

Cognoscitivamente, los usuarios en un museo interactivo son considerados personas en situación. Una situación inmediata que es la construida específicamente por el museo para facilitar el logro de sus objetivos y otra más mediata o contextual, que prevalece en la cotidianidad de cada individuo y que no se abandona al entrar al museo, sino que permanece latente en la nueva situación, mediando de alguna manera su experiencia y aprendizaje con los distintos aspectos museográficos.

Esta concepción conlleva varias implicaciones. Una de ellas es que cada exposición debe de estar en consonancia con el perfil del usuario común, no de un usuario idealizado o un usuario en abstracto; y aunque al inicio se parta de un conocimiento mínimo o preliminar de sus niveles y estilos cognoscitivos, uno de los desafíos de cualquier museo de la cuarta generación es la realización de investigación sistemática permanente que permita en el futuro afinar mejor el conocimiento específico de sus propios usuarios, para adecuar de manera más idónea sus diversos elementos con su perfil cognoscitivo y cultural.

Este desafío es especialmente importante, no tanto por la necesidad de determinar con precisión los niveles de desarrollo cognoscitivo de los usuarios, sino por compaginar los conocimientos científicos especializados que ofrezca el museo con sus costumbres, estilos comunicativos y ritualidades culturales (Vigotsky, 1988), y aun con sus experiencias sociales (Gutiérrez y Prieto, 1991) y memorias colectivas (Martín- Barbero, 2002).

En esta perspectiva se asume que la capacidad cognoscitiva no viene determinada únicamente por los estadios del desarrollo intrínseco del individuo, sino también por la convergencia de ese desarrollo particular con las características de su contexto social (Piaget, 2000; Chomsky, 1979; Gardner, 1983). Por tanto, se considera que no son los esquemas mentales, ni los coeficientes intelectuales -entendidos ambos como estructuras individuales intrínsecas- los únicos que determinan lo que una persona puede aprender, sino que son las oportunidades y la calidad del diálogo social que tenga una persona lo que más influye posteriormente para el desarrollo pleno de su potencial de aprendizaje (Howe, 1999; Freire, 1998).

De aquí que los museos contemporáneos de la cuarta generación, pongan especial cuidado sobre todo en el tipo y el sentido de la interacción y sus posibles variaciones entre los objetos y los usuarios, ya que ambos suponen un proceso comunicativo y son una fuente de expresividad y una oportunidad de desarrollo de la creatividad que se reactiva en cada encuentro.

Como dice Maturana (1999) la misma individualidad es producto, no causa, de la interacción con los otros. Es esta interacción, entonces, y no la individualidad la instancia primaria, desde donde va surgiendo el distintivo de cada persona. En este sentido, el leit motiv de un aprendizaje y en definitiva del desarrollo humano consiste justamente en la posibilidad de que cada persona, y los niños en particular, sea co-creador de espacios y 
situaciones que a su vez sirvan para ampliar la capacidad de desarrollo humano tanto de ella misma, como de los otros con los que interactúa.

Lo anterior lleva a especificar que el dispositivo museográfico cuente con módulos adecuados para la organización de espacios y situaciones material-simbólicas desde donde puedan producirse distintos tipos de aprendizajes y construirse diversos tipos de conocimiento (Cohen, 1997). Asimismo, estas situaciones deben permitir la socialización de los aprendizajes individuales, por una parte y, por otra, anticipar el hecho de que los usuarios pueden llegar solos o integrando una comunidad familiar, de amigos o un colectivo mayor. Por ejemplo, un grupo escolar, cuyas composiciones también mediarán su interacción y resultados en su exploración del Museo (Caulton, 1998).

El museo, en tanto escenario donde se pone en escena el conocimiento y se realizan diversos aprendizajes, es una "plataforma viva" que puede también activarse de diversas maneras y surcarse a través de varias rutas. Por esto, en los museos contemporáneos no hay una única manera en la que sus usuarios puedan hacer sus recorridos, sino varias, estructuradas de acuerdo a situaciones específicas previsibles y siempre en conjunción con los diferentes módulos y objetivos cognoscitivos de cada museo.

Al concebir a sus usuarios como personas en situación o entes fundamentalmente sociales, un museo interactivo entiende que lo cognoscitivo es un compuesto por lo menos de cuatro elementos: razón, acción, comunicación y cultura, por lo que asumir esta dimensión cuádruple de manera integral supone a su vez entrelazar en una cadena sin final lo racional con lo emocional, la curiosidad con la motivación por conocer y la gratificación por conocerlo, la comunicación con la acción y la acción con la reflexión y la creatividad con los valores universales y los estilos locales.

El usuario de un museo interactivo es finalmente comprendido como un ser social activo, en permanente interacción consigo mismo, con los otros y con su entorno, capaz de construir conocimientos y de hacer interpretaciones a partir de esa interacción. Un ser social capaz también de disfrutar e interesarse por responder a los desafíos planteados, dispuesto a involucrarse intelectual, emotiva y físicamente con el dispositivo del museo, y a compartir sus descubrimientos con los otros a través del diálogo y la colaboración efectiva, solidaria y comprometida. $Y$ un ser capaz también de resistencia, que podrá no sentirse atraído en algún momento por alguna de las opciones del recorrido. Hay que recordar aquí lo que Freire y los grandes pedagogos (por ejemplo, Dewey, Montessori, Freinet, McLaren) siempre han dicho: "no hay docencia sin disencia".

En los museos interactivos se debe de estar consciente también de que no existe el "usuario ideal", sino que la realidad a veces limita, reprime o bloquea las capacidades humanas de las personas, por lo que cualquier museo en tanto institución cultural y educativa tendrá que asumir el desafío de buscar desarrollarlas para contribuir a la creación de usuarios que puedan potenciar lo más posible su interacción con la oferta y los objetivos museográficos. Pero sobre todo usuarios, que en tanto personas, se vuelvan cada vez más inquisitivos, activos y reflexivos a partir (y más allá) de sus viajes museográficos, y sobre todo que se vuelvan cada vez más creativos.

Comunicativa y culturalmente se debe de considerar a los usuarios de un museo interactivo como miembros de una cultura particular y, en específico, de una "comunidad de interpretación" (Fiske, 1983; Jensen, 1987). 
Este tipo de comunidad conlleva un sentido metafórico o simbólico, que busca reflejar la convergencia de varias personas en una misma perspectiva sobre el mundo o cosmovisión. Las principales comunidades interpretativas para los niños son su familia, su escuela y su grupo de amigos (Orozco, 1988). Una comunidad interpretativa, entonces, funciona como esa dimensión desde donde sus miembros producen y dan sentido a sus interacciones cognoscitivas, materiales y emocionales de acuerdo a ciertos códigos y tradiciones, estilos y valores compartidos.

Empíricamente se ha visto cómo varían las apreciaciones y percepciones que los usuarios de los museos contemporáneos tienen, incluso de exposiciones de tipo más estático o históricas, menos interactivas, lo que permite suponer que, en última instancia, el o los efectos educativos que pueda tener un museo en sus usuarios son productos o resultantes siempre de varias fuentes (Macdonald y Fyfe, 1996)

Desde el ámbito de disciplinas como la comunicación y la semiótica se sabe que el niño y por supuesto también el adulto- participan a la vez de varias situaciones, naturales o fabricadas y organizadas, en las cuales "negocian" significados y se apropian o resisten aquellos propuestos por otros, resultando en una re-producción del orden social o en una resistencia de él, pero siempre en una producción interpretativa (Hall, 1982).

En este intercambio intervienen -además de los esquemas mentales- los repertorios culturales y los guiones sociales. Los "repertorios culturales" son justamente eso, repertorios, conjuntos de informaciones, configurados por la acumulación de aprendizajes anteriores, producto a su vez de otras experiencias que sirven de bagage desde donde los sujetos connotan su producción creativa, cultural (Orozco, 1990).

Los "guiones sociales" consisten en secuencias significativas de acción y reflexión, aprendidas por los sujetos para su sobrevivencia cultural y para guiar su actividad en el mundo. Desde el cómo saludar, cómo preguntar o cómo contestar hasta el cómo sentarse, caminar o pasear en un recinto cerrado o abierto, conllevan guiones o modos particulares que son culturalmente determinados y aprendidos con una significación específica y varían de cultura en cultura.

Un museo interactivo de la cuarta generación asume que sus usuarios no llegan a sus instalaciones vaciados de significados, ni como individuos culturalmente atomizados, sino como representantes de una cultura y a la vez copartícipes de procesos concretos de (in)comunicación y significación en los que adquieren sentido sus particulares interacciones y aprendizajes.

La aspiración de un museo en este rubro es entonces la de contribuir a la ampliación de los repertorios culturales y científicos de sus usuarios, a la transformación de sus guiones en comportamientos, actitudes $y$ disposiciones mucho más propicias para la experimentación y evaluación de conocimientos y el fortalecimiento de sus habilidades de comprensión, para una mejor selección y análisis de la información con la que interactúen y en última instancia para una mejor comunicación.

Otro de los intereses pedagógicos de un museo interactivo es propiciar la emergencia de nuevas interpretaciones, más finas, más profundas, más complejas, justamente a través de facilitar la incorporación de sus usuarios en comunidades intencionadas de "apropiación" (Orozco, 1995) que son básicamente comunidades de interpretación y comunicación con el propósito explícito de aprendizaje. 
En estas "comunidades de aprendizaje", a partir de la socialización entre sus miembros, se van construyendo conocimientos y produciendo comprensiones sobre objetos y situaciones específicas (Cole, 1985; Savater, 1997).

Si la cultura es tanto una creación-producto tangible, como una perspectiva o mirada no tangible, desde la cual se produce y se crea, entonces un reto de un museo contemporáneo es el de seleccionar los objetos y diseñar los espacios, bajo el entendido de que estos sólo adquieren su pleno sentido en la interacción que se propicie con sus usuarios.

Por este motivo hay que especificar las definiciones de esa "mirada" o perspectiva desde donde los sujetos tienen que "aprehender" los objetos e informaciones para arribar a su re-descubrimiento y a otros aprendizajes posibles a través de ellos. Es de la conjunción de objeto y mirada de donde se producirá una interpretación, sin que esto anule la propia capacidad expresiva y significativa de los objetos.

En la medida en que los objetos, la mirada y los espacios se desplieguen adecuadamente, se abrirán las posibilidades para que la interacción con el usuario de un museo interactivo fructifique en aprendizajes significativos y para que se fortalezca su creatividad (Savater, 2000).

Pedagógicamente, el usuario en los museos interactivos es entendido como una persona en formación $y$ desarrollo intensivos. Una persona susceptible de ser convocada a experiencias de aprendizaje múltiple y a involucrarse de manera variada con el dispositivo museográfico.

Este usuario activo, y a veces hasta hiperactivo, incansable, y hasta un cierto grado impredecible, como lo son el niño y el joven, no son asumidos como meros recipientes de conocimientos exteriores, independientemente de la calidad y oportunidad de estos. Como enfatizó Freire (1970) la cabeza de nadie es un banco en la cual --en lugar de dinero- haya que depositar la información y los conocimientos.

No se considera que la función de un museo interactivo sea una de simple transmisión de conocimientos y saberes. Si bien en las salas de cualquier museo y en otros espacios dentro de todo el conjunto arquitectónico que lo conforman se presenta una oferta rica y variada, su objetivo no es llenar con ella las cabezas de los usuarios, ni simplemente saciar sus sentidos, sino provocar y facilitar encuentros alternativos, para que de ahí se construyan aprendizajes significantes.

Desde esta perspectiva, el verdadero aprendizaje no se produce desde afuera sino sólo desde dentro de la persona, desde lo más profundo de su ser. Por eso en un museo interactivo no se invita a los niños a copiar, imitar o seguir sin reflexión líneas previamente establecidas. En lugar de eso, el dispositivo museográfico sugiere opciones y rutas alternativas, muestra ejemplos e invita a los niños a que ellos hagan su propio recorrido y exploración.

Con todo este esfuerzo se busca que el usuario vaya haciendo evidente por sí mismo el desafío que tiene ante él, las posibilidades de enfrentarlo con éxito y las oportunidades de construir conocimiento desde ahí (Orozco, 2002). 
El énfasis pedagógico está en la problematización de conocimientos, vía el planteamiento de preguntas, no de respuestas, que faciliten un diálogo múltiple tanto con la información o conocimiento nuevo, como con conocimientos viejos anteriores y con los otros participantes de la misma exploración dentro del museo.

Lo que se pretende con este énfasis es fortalecer la curiosidad, mientras se refuerzan las capacidades de análisis, reflexión, discusión, expresión y gestión de los participantes en el proceso educativo dentro de los museos.

Por curiosidad en un museo interactivo deberá entenderse esa inquietud profunda del usuario en tanto persona por conocer y conocerse y por tratar de ir más allá del límite de lo que es evidente a los sentidos para incursionar en su análisis y en su explicación y así arribar a una comprensión más profunda de los diferentes elementos involucrados en aquello que se está conociendo.

En definitiva, pedagógicamente se considera al usuario de un museo interactivo como un ser activo y naturalmente curioso, capaz de crecer simultáneamente en varios sentidos, pero al que hay que apoyar especialmente para que avance en el desarrollo de sus capacidades inquisitiva, analítica y expresiva. Y este avance sería fundamentalmente un avance en el desarrollo de su creatividad, entendiendo por tal un proceso por el cual efectivamente la persona trasciende límites existentes y abre nuevas posibilidades para seguir trascendiéndolos.

Como ha enfatizado el educador-comunicador uruguayo Mario Kaplún (1998) "hay que pasar de formar educandos oyentes, a formar educandos hablantes", porque sólo hasta que el conocimiento sea expresado por los sujetos podemos saber que se ha producido su aprendizaje. Pero también porque la expresión conlleva un componente emancipatorio. Por ello, en los museos interactivos se hace especial énfasis en que el equipo de guías propicie el diálogo con los usuarios. No se trata sólo de darles indicaciones. Los guías tienen la tarea específica de invitar y facilitar también el involucramiento verbal entre todos.

\section{El proceso de aprendizaje}

Partiendo de una comprensión en la que se asume que en la educación lo sustantivo no es la transmisión de conocimientos, sino su construcción conjunta, se puede destacar, en primer lugar, que el aprendizaje no es entonces un momento o un acto, sino una serie de momentos en secuencia. El aprendizaje es un proceso largo y complejo en el que se van tejiendo, problematizando y discutiendo nociones y saberes, creencias y afectos a partir de la interacción --en este caso- con el dispositivo museográfico.

En el proceso de aprender, los roles de los participantes necesariamente se intercambian. El educador se hace educando y viceversa, lo mismo que el emisor se hace receptor, y éste a la vez emisor de su "nueva palabra" o su "nueva imagen" o su "nuevo sonido" y, en definitiva, de su nueva interpretación.

La complejidad del proceso de aprendizaje estriba en que aprender involucra la totalidad del ser (Maturana, 1999). Cuando realmente se aprende es porque se han movilizado distintas dimensiones. Por una parte, la racional, pero, por otra, la emocional, la estética, la simbólica o la psicomotriz, sobre todo cuando la interacción con el conocimiento involucra la acción y se produce vía la interactividad física y/o virtual (Dede, 2000; Duart y Sangrá, 2000). 


\section{¿Por qué se aprende?}

Cuando se hace la pregunta de por qué se aprende, se puede contestar fundamentalmente de dos maneras. Una, se aprende porque alguien nos enseña algo que quiere que aprendamos y lo hace a través de diversos métodos. La otra manera es porque lo descubrimos, vía la exploración, el ensayo y error.

Cuando se trata de la primera respuesta, estamos inscribiendo nuestro entendimiento del aprendizaje dentro de un "paradigma de la imitación" o del modelaje, sea en el caso de que un conocimiento o modelo sea enseñado específicamente o simplemente apropiado y seguido por aquel que lo aprende o lo imita. Cuando damos la segunda respuesta estamos circunscritos por el "paradigma del descubrimiento".

Las diferentes teorías del aprendizaje finalmente se reducen a estos dos grandes tipos, ejemplificados por esos dos paradigmas: imitación y descubrimiento.

En un museo interactivo se deben de combinar ambos paradigmas -aunque se enfatice el del descubrimiento por obvias razones-, ya que si bien se considera que como institución social y cultural un museo tiene algo que decir y ofrecer como aprendizaje a los usuarios, no por eso se pretende que ellos simplemente copien o memoricen los conocimientos ahí reunidos y desplegados.

Lo que se busca con esta actitud, que a la vez es un principio fundamental, es que a partir de esos conocimientos, ofertados con métodos y estrategias adecuadas para ser aprendidos, los usuarios construyan nuevos aprendizajes, para lo cual la manera de ofrecerlos no es como en la típica y tradicional situación de la enseñanza que se conoce como instrucción (Gutiérrez y Prieto, 1993). Por el contrario, en un museo de la cuarta generación se buscaría educar en el amplio sentido de la palabra y se trataría de inspirar y facilitar la construcción múltiple de aprendizajes. La ambición de un museo como institución trasciende la mera instrucción y busca ampliar los horizontes de los usuarios, no sólo en conocimientos, es decir en productos, sino sobre todo en procesos, estrategias y métodos de aprendizaje.

Si algo distingue la educación contemporánea de la de otras épocas es, por una parte, la creciente multiplicación de fuentes y escenarios de aprendizaje y, por otra, la explosiva transformación de sus procesos y estrategias de producción de conocimientos y saberes (Pérez-Tornero, 2000).

La presencia de los medios de comunicación y de las más modernas tecnologías de información significan no solamente cambios profundos en la difusión y alcance masivo de saberes y conocimientos, sino hondos sacudimientos en sus procesos mismos de gestación (Vilches, 2002).

No es la persona frente a una nueva máquina lo que constituye la fuente principal de los cambios, como era el caso en la revolución industrial, sino la inauguración de nuevas relaciones entre cerebro e información codificada, entre esquemas cognoscitivos y formatos narrativos, entre razonamiento abstracto y "visualidades" tecnificadas, lo que está definiendo la nueva producción de conocimientos (Castells, 2000; Martín-Barbero y Rey, 1999).

Los criterios de legitimación de conocimientos por consecuencia están cambiando. Mientras se desdibuja la racionalidad de la lógica clásica (tesis, antítesis, síntesis) 
adquieren hegemonía las "racionalidades transversales" y en especial audiovisuales de las diferentes pantallas con las que actualmente interactuamos, en las que la percepción y los sentidos se tornan los últimos reductos de la legitimidad del conocimiento (Orozco, 2001).

Frente a este desafío tecnológico de nuestro tiempo, los museos de la cuarta generación tratan de montar su dispositivo multimedia combinando viejas y nuevas estructuras, formas y superficies, pero sobre todo incluyendo diferentes módulos videoelectrónicos y digitales con los cuales se facilite, y a la vez sea innovativo, el "viaje" de los usuarios por el museo y se amplíe su recorrido más allá de los límites espaciales del propio recinto y de las exposiciones y módulos particulares ahí contenidas.

En los museos interactivos se espera que los usuarios una vez que hagan ensayos a lo largo de su recorrido o recorridos los trasladen a otras situaciones y los hagan también en otros escenarios de su vida cotidiana. Esto es una posibilidad real en la medida en que el aprendizaje rebasa a la enseñanza, lo cual significa que siempre se puede aprender y que de hecho se aprende sin que medie una intención específica de hacerlo ni por parte del que aprende, ni por parte de ningún otro educador.

Trascender métodos convencionales de aprendizaje y de instrucción supone varias cosas. Una de ellas es el uso de una metodología lúdica. Con ella los museos interactivos buscan hacer realidad una manera de aprender jugando, donde, no obstante, no se trataría de jugar por jugar o divertir por divertir -aunque una buena diversión tenga un alto valor pedagógico y motivacional intrínseco-. Más bien, el juego se asume como una situación pedagógicamente privilegiada para descubrir y especialmente para disfrutar la construcción de aprendizajes relevantes para la vida (Orozco, 2002).

El juego es una excelente estrategia de simulación. Cuenta con ciertas reglas y unos objetivos. Por supuesto hay roles asignados y orientaciones para llegar a la meta. Hay varios jugadores y por lo general se participa como miembro de un grupo, de un equipo, lo que garantiza la parte colectiva y social del proceso cognoscitivo. Más aún, en el juego hay un desafío, hay conflicto, hay que poner en marcha y ejercitar varias destrezas simultáneamente: análisis, evaluación, reflexión, planeación, ejecución (por lo menos), que en otros procesos tradicionales de educación se soslayan y hasta se sacrifican en aras de memorizar al pie de la letra las inflexibles normativas del instructor.

La pedagogía lúdica ha probado ser una pedagogía natural o "conatural" al ser humano en tanto que el juego es una parte esencial de la vida, no sólo de los niños, sino también de los adultos, aunque no siempre se reconozca así. Además, el juego es una actividad propicia para ejercitar la creatividad y poner en operación una serie de destrezas manuales y mentales adecuadas para trascender situaciones límite y superar obstáculos (Next Generation Forum, 1999).

Con base en otras experiencias de aprendizaje lúdico con niños y jóvenes (Cobian, 1999; Echeverría, 2000) es posible pensar que cuando el proceso además de ser lúdico y hacerse divertido se "sensorializa" (Coleman, 1997), esto es, se realiza simultáneamente a través de la razón y de varios sentidos, el aprendizaje resultante es más profundo y permanente, más significativo, que si sólo se emplea la razón y el proceso se desenvuelve en una dimensión abstracta (Ferrés, 1996; Savater, 2000).

Tocar un objeto y manipularlo, permite una percepción del mismo muy diferente a sí solamente es visto. Desde la comunicación se sabe que cada sentido otorga un 
conocimiento complementario y un matiz distintivo a la totalidad del objeto en cuestión (Postman, 1995).

Otra de las maneras de trascender la instrucción lineal en un museo interactivo es precisamente la interactividad. Se considera que el involucramiento multidimensional: corporal, sensorial, mental, simbólico y virtual de los usuarios en un museo es un elemento que facilita alcanzar sus objetivos de aprendizaje, a la vez que les permite hacerlo mejor, en la medida en que no sólo la razón se involucra, sino también los sentidos y los músculos, ya que hay movimiento real.

Según varios autores, entre ellos Kozma y Shank (2000), Freire (1998) y Caulton (1998), la interactividad permite la acción del sujeto sobre el objeto de aprendizaje, no sólo su contemplación. La interactividad específica en un museo permite una apropiación dinámica tanto de los conocimientos desplegados, como de los diferentes elementos del dispositivo museográfico. Y la experiencia internacional va mostrando cómo también la motivación y el interés se refuerzan y expanden cuando los usuarios pueden interactuar con las exposiciones y manipular sus diversos objetos (Domenech et Al, 2002).

Si se quiere que un museo sea un escenario de exploración y descubrimiento, la condición es que su dispositivo permita la interacción manual, real o virtual. La apuesta aquí es que además e independientemente de que la interacción estimule y mantenga el interés de los usuarios, facilite también su aprendizaje al conectar pensamiento y acción (Dede, 1998). Así, "de manos a la obra" se transita más adecuadamente a "mentes a la obra" y viceversa (Caulton, 1998).

\section{¿Cómo se aprende?}

Para contestar esta pregunta es recomendable apoyarse explícitamente en las tesis de autores como Vigotsky (1978), Luria (1984), Pérez (1999) y Cole (1985), que a partir de Piaget (1970) han elaborado una fina propuesta que se conoce como la "Zona del Desarrollo Próximo o Proximal".

Esta zona se refiere a esa diferencia entre la capacidad real de aprender de una persona y su capacidad potencial que se hará realidad justamente a través de su educación. En palabras del mismo Vigotsky (1998, p. 133):

La zona proximal de desarrollo es la distancia entre el nivel actual de desarrollo, determinado por la capacidad de resolver independientemente un problema, y el nivel de desarrollo potencial, determinado a través de la resolución de un problema bajo la guía de un adulto o en colaboración con otro compañero más capaz

De acuerdo a esta propuesta, se aprende por el desafío cognoscitivo. Cuando somos desafiados a transitar de un nivel de desarrollo inferior a otro superior o mayor, pero posible de alcanzar con un esfuerzo y con la guía de un adulto, en el caso de los niños, o de un compañero cuyo desarrollo esté en un nivel más alto.

Freire había arribado a una propuesta similar, en tanto que él hablaba de "situaciones límite". Una vez llegada una situación de éstas como resultado de la problematización que se hacía al conocimiento anterior, el salto requerido era salir para ubicarse en una situación distinta, que posteriormente se tornaría límite también y habría que volver a trascender. 
Tanto en una como en otra perspectiva conceptual, el acompañamiento activo del otro en el proceso es fundamental. Sin embargo, no se trata de cualquier acción o acompañamiento. La mediación del otro en el proceso educativo está dirigida a ayudar a la persona a dar el salto correctamente y a ubicarse así en un estadio superior de conocimiento (Del Río, 1999).

No se trata de imponer nada ni de anular al aprendiz con exceso o con prepotencia, o con un desafío desmesurado, sino todo lo contrario (Pérez, 1999). El autoritarismo y la imposición eclipsarían el esfuerzo educativo auténtico en la medida en que neutralizan el aprendizaje potencial (Giroux, 1994).

Un museo interactivo se interesa especialmente por sustentar su propuesta en las zonas de desarrollo proximal de sus usuarios para ubicar su acción educativa de tal manera que en forma colectiva y con la intervención especializada de su equipo de guías y, por supuesto, con el despliegue adecuado de sus exposiciones y orientaciones escritas y audiovisuales se haga posible el desarrollo y el aprendizaje de todos sus usuarios a partir de su exploración museográfica.

Una de las premisas centrales en un museo interactivo sería la de ser un "museo para todos", no sólo para algunos. Esto a su vez supone cumplir con las condiciones de calidad profesional que permitan llegar a tal objetivo, así como actuar siempre con el convencimiento de que todos los usuarios pueden aprender y aprender más, y de múltiples maneras, a partir de su exploración museográfica. La esperanza aquí es que los usuarios de un museo no lo sean una sola vez, sino que se conviertan en "usuarios asiduos" o recurrentes, que con la repetición de visitas al museo vayan "cultivando" tanto su estatus de usuarios de un museo contemporáneo, como sus aprendizajes particulares.

\section{Los contenidos y su sentido}

Si algo ha caracterizado siempre a los museos a lo largo de su existencia es ser recintos que contienen o albergan una serie de conocimientos y saberes, de contenidos e informaciones, de interpretaciones al fin y al cabo, que se coleccionan por expertos y se despliegan por diseñadores a los visitantes. Este ha sido el caso de los museos tradicionales que buscan preservar la memoria histórica de un pueblo o nación, o conservar para la posteridad algún tipo de producto cultural, o de aquellos otros más especializados que abordan un subcampo artístico o disciplinario. Esta apreciación sólo muy parcialmente sigue siendo válida para los museos contemporáneos de la cuarta generación.

Puesta en perspectiva la evolución museográfica, lo que se ha transformado -como se ha explicitado al principio- son los fines o "para qué", los medios o "métodos", esto es, los "cómo", y por supuesto también el proyecto cultural-educativo particular que anima y organiza todo el dispositivo museográfico y le otorga una intencionalidad y un sentido concretos a los museos.

En los fines, se ha transitado de la conservación o preservación (que ha inspirado y legitimado a la mayoría de los museos) a la "provocación" estética o cognoscitiva como finalidad general, entendiendo por tal una invitación al usuario para hacer suyo el desafío de aprendizaje al que se le enfrenta. 
En los métodos, se ha pasado de la exposición exhaustiva o selectiva, para la contemplación y subsiguiente admiración de los espectadores, a la interactividad o interactividades (ya que hay varios tipos y niveles) pasando por etapas con distintos grados de involucramiento sensorial, mental y manual-corporal de los usuarios con el dispositivo del museo.

Ha habido también cambios sustantivos en los "sentidos" o motivos y criterios para conjuntar y exponer los contenidos de la oferta museográfica, pasando de los estrictamente estéticos, históricos o simbólicos a los de "utilidad pedagógica", lo que ha derivado finalmente en la necesidad de elaborar un proyecto educativo particular que guíe la conformación global del museo.

Por "utilidad pedagógica" hay que entender esa intencionalidad que persigue un museo para facilitar el crecimiento educativo integral de sus usuarios y no sólo para propiciarles un rato agradable o divertido, sorprenderlos o simplemente darles alguna nueva información.

En un museo de la cuarta generación se busca que el viaje de los usuarios o ir a su recinto les sea útil de varias maneras. Por ejemplo, para complementar y profundizar aspectos de su educación formal en las escuelas o para despertarles la imaginación como ingrediente fundamental para echar a andar su creatividad o para facilitarles descubrimientos, comprensiones, insights o entendimientos profundos sobre aspectos particulares del mundo de la vida, del arte, de la ciencia y de la tecnología.

Algunos museos, como el Science Museum, de Londres, han incluido la "interactividad virtual" sustentada en estrategias de multimedia que integran dispositivos que físicamente trascienden el recinto museográfico.

Esta modalidad de interacción conlleva navegación por Internet y "viajes" en cápsulas que reproducen procesos y realidades en varias dimensiones, así como la "Experiencia IMAX" que bombardea la percepción audio-visual de los usuarios al sumergirlos en contextos no tangibles de sonidos e imágenes.

En los museos interactivos generalmente se comparte esta intencionalidad y por ello se insertan amplios dispositivos multimedia y otras facilidades audiovisuales y digitales, siempre buscando que los usuarios puedan trascender mental y sensorialmente su exploración material del museo.

El valor educativo en este esfuerzo, que es lo que lo justifica, y que consiste en qué ver y escuchar y, finalmente, sentir desde otra dimensión, permite tomar conciencia de la propia y, sobre todo, concebir que es posible su transformación, en la medida en que la persona se sitúa al borde o al filo de lo conocido o experimentado antes o hasta ese momento.

El proceso o secuencia cognoscitiva que se desarrolla con la virtualidad arranca con la percepción de que siempre hay más, luego continúa con la percepción de que todo puede ser o hacerse de otra manera, lo cual es la condición sine qua non para, a su vez, apreciar que los hechos no se producen por necesidad histórica, sino que todo siempre pudo haber sido diferente. $Y$ esto finalmente permite sembrar en la mente y en la voluntad la "semilla" del cambio. 
Anticipar o prefigurar una transformación es a su vez la condición más importante para activar la creatividad. Sin ella no tendría mucho sentido pensar en el futuro, ni en el presente, ni mucho menos en el pasado, ya que la creatividad arrancaría justamente con una recuperación crítica de la historia.

La reflexión internacional actual sobre la educación y sus fines en el tercer milenio justamente propone tener como fin de la formación de las generaciones contemporáneas el constituir con ellas una "sociedad creativa" o sociedad de la creatividad (Next Generation Forum, 1999; Echeverría, 2000).

Este tipo de sociedad es aquella donde uno de los valores centrales se otorga a los niños y a su educación para que se formen como seres responsables, capaces de transformar su mundo, precisamente a través de actos creativos individuales, pero compartidos (Reznick, 1999).

Lo creativo se entiende como ese esfuerzo a través del cual permanentemente se rebasan los límites del conocimiento y la acción en el compromiso por ser más como persona y como miembro de una comunidad, no simplemente en tener más. Este proceso entonces conlleva un permanente sentido de trascendencia, no de competencia (Orozco, 2002).

Uno de los fines de esta sociedad creativa es la constitución de comunidades de aprendizaje, cuyos criterios vayan en función de valores como la solidaridad, la tolerancia, la diversidad, la superación individual y comunitaria y el aprendizaje a lo largo de la vida (OEI, 2000).

En la búsqueda de una sociedad creativa, los dispositivos tecnológicos de los museos interactivos por lo general no responden al principio de modas, o de racionalidad tecnocrática, sino al de "racionalidad sustantiva", lo que significa que el herramentaje mecánico, electrónico y digital adquiere su sentido no como tecnología en sí misma (Aparici, 2000), ni como vehículo transmisor de contenidos, sino como facilitador perceptivo de su producción (Next Generation Forum, 1999). Lo sustantivo no radica en la importancia subjetiva del referente que se retrae, sino en su potencial contribución a los procesos cognoscitivos de alto nivel: inferencia, explicación y evaluación. Procesos estos que se ponen en marcha a partir de interactuar con módulos constituidos con aparatos y pantallas.

La comprensión que hacen los museos interactivos de la tecnología videoelectrónica o digital o cualquier otro tipo de tecnología no es la de un fin en sí misma, aunque tampoco sólo la de un mero vehículo neutral de contenidos. La tecnología es entendida, más que nada, como una estrategia de percepción y lenguaje, conocimiento y acción que supone producción, clasificación, tratamiento y apropiación de información de acuerdo a fines y criterios concretos (Martín-Barbero, 2000).

En muchos museos interactivos los fines, en última instancia, tienen que ver con el "empoderamiento" de los usuarios (Giroux, 1994; McLaren, 1997) para responder a los desafíos múltiples que les depara el mismo dispositivo museográfico y que en su momento mutatis mutandi les depare la vida y su crecimiento integral como personas y como miembros de una comunidad. 
Cuando se alude al "empoderamiento" se está haciendo referencia a un aumento real de la capacidad de transformación de las personas para crecer como tales y para actuar eficazmente sobre su entorno a partir de actos creativos y libres que se espera que sean cada vez más autónomos, afirmativos e informados.

Por esto el empleo de tecnologías, herramientas y aparatos diversos en las salas de un museo debe obedecer a una elaboración reflexionada y específica del propio museo acerca de nuevas maneras de comunicar y procesar información que sean coincidentes con los principios y criterios que lo sustentan y con la misión que lo anima.

Con base en la premisa pedagógica de que la educación artística del niño y el joven es esencial para estimular su crecimiento integral, los museos de la cuarta generación, especialmente aquellos en tierra latinoamericana, donde la expresión colectiva e individual ha sido casi siempre reprimida, tienen que desplegar algunos módulos para estimular explícitamente la expresividad de sus usuarios.

El potencial de los museos interactivos en gran parte está aún por hacerse realidad, pero la conjunción de disciplinas como la comunicación y la educación, y el trabajo coordinado de comunicadores y pedagogos son dos de las condiciones claves para lograrlo.

\section{Referencias bibliográficas}

Aparici, Roberto. "Trece mitos sobre las nuevas tecnologías de la información y de la comunicación", en Tabanque, N 14. Valladolid, pp. 45-53.

Castells, Manuel. La era de la información. México: Siglo XXI, 1999.

Caulton, Tim. Hands-On Exhibitions. Nueva York: Routledge, 1998.

Cobian, María et alii. "Contexto sociocultural y aprendizaje significativo", en Educar, N 9. Guadalajara, México, pp.41-50.

Cohen, Dorothy. ¿Cómo aprenden los niños?. México: Fondo de Cultura Económica, 1997.

Cole, Michel. "The Zone of Proximal Development, where culture and cognition creates each other", en Wertsch, ed. Culture, Communication and Cognition, Vitgoskyan Perspectives. Cambridge: University Press, 1985.

Chomsky, Noam. Language and Responsibility. Estados Unidos: Pantheon Books, 1979.

Dede, Chris. Aprendiendo con tecnología. Buenos Aires: Paidós, 1998.

Del Río, Norma. "Bordando sobre la zona de desarrollo próximo", en Educar, N 9, 1999, pp. $8-12$.

Doménech, Miquel et alii. El discurso de los objetos. Museo y comunicación pública de la ciencia. (Manuscrito).

Duart, Joseph, y Sangrá, Albert. Aprender en la virtualidad. Madrid: Gedisa, 2000. 
Echeverrría, Javier. "Quince propuestas para una política educativa en el tercer entorno", en Tabanque, Núm. 14, 2000, pp. 12 - 20.

Ferrés, Joan. Televisión subliminal. Barcelona: Paidós, 1996.

Fiske, John. Power plays, power works. Nueva York: Verso, 1993.

Freire, Paulo. Pedagogía del oprimido. México: Siglo XXI, 1970.

Pedagogía de la autonomía. México: Siglo XXI, 1998.

Pedagogy of the Heart. Estados Unidos: Continuum, 1998.

Gardner, Howard. Art, mind and brain. Nueva York: Basic Books Inc., 1982.

. Frames of mind. Nueva York: Basic Books Inc., 1985.

Giroux, Henry. Disturbing Pleasures. Londres: Routledge, 1994.

Goleman, Daniel. La inteligencia emocional. México: Javier Vergara, 1997.

Gutiérrez, Francisco, y Prieto, Daniel. La mediación pedagógica. San José: Rafael Landívar, 1991.

Hall, Stuart. "The rediscovery of ideology", en Gurevitch, Michael et alii. Return of the repressed in media studies. Nueva York: Methuen, 1982.

Howe, Michael. Genius Explained. Cambridge: University Press, 1999.

Jensen, Klaus. "Qualitative audience research: toward an integrative approach to reception", en Critical Studies in Mass Communication, Vol. 4, No. 1, 1987, pp. 21 - 37.

Kaplún, Mario. Una pedagogía de la comunicación. Madrid: la Torre, 1998.

Kozma, Robert, y Shank, Patricia. "La tecnología como soporte de la reforma educativa", en Dede, Chris, comp. Aprendiendo con tecnología. Quilmes: Paidós, 2000.

Luria, Alexander. Conciencia y lenguaje. Madrid: Visor, 1984.

MacDonald, Sharon, y Fyfe, Gordon. Theorizing Museums. Inglaterra: Blackwell Publishers, 1996.

Martín-Barbero, Jesús. Ejes estratégicos de Investigación en el campo de los estudios socioculturales. México: ITESO, Documento de Trabajo, 2000.

Nómadas No. 16, 2002.

"La crisis de las profesiones en la sociedad del conocimiento", en Revista

Martín-Barbero, Jesús, y Rey, Germán. Los ejercicios del ver. Barcelona: Gedisa, 1999.

Maturana, Humberto. Transformación en la convivencia. Santiago de Chile: Dolmen, 1999. 
McLaren, Peter. Revolutionary Multiculturalism. Pedagogies of dissent for the new millennium. Estados Unidos: Westview. 1997.

Next Generation Forum. Toward the Creative Society, Annual Report. Copenague: LEGO Company, 1999.

Organización de Estados Americanos -OEI-. "Dossier sobre Reformas Educativas: mitos y realidades”, en Revista Iberoamericana de Educación, 2001.

Orozco, Guillermo. "Del sujeto individual al sujeto colectivo en la educación para la recepción”, en Orozco y Charles. Hacia una lectura crítica de los medios”. México: Trillas, 1990.

Televisión, Audiencias y Educación. Colección Enciclopedia Latinoamericana de Sociocultura y Comunicación. Buenos Aires: Editorial Norma, 2001.

"Television as a Toy". Ponencia presentada en el Tercer Congreso Internacional "Toys, Games and Media" . Inglaterra, University of London Institute of Education, agosto de 2002.

No. 2. 1995.

"The Dialectic of TV Reception", en The Mexican Journal of Communication,

Paris, Scott. Perspectives on Object - Centered learning in museums Nueva Jersey: Lawrence Elbaum, 2002.

Pérez, Gilberto. "La zona de desarrollo próximo y los problemas de fondo en el estudio del desarrollo humano desde una perspectiva cultural", en Educar, N 9, 1999, pp. 12 - 22.

Pérez-Tornero, José M., comp. Comunicación y educación en la sociedad de la información. Barcelona: Paidós, 2000.

Piaget, Jean. El desarrollo de la inteligencia. México: Fondo de Cultura Económica, 1970.

Económico, 2000.

. La Construcción del símbolo en el niño. México: Fondo de Cultura

Postman, Neil. El fin de la educación. Barcelona: Eumo octaedro, 1995.

Reznick, Mitchel. "Enabling the creativity society", en Next Generation Forum: Toward the Creative Society, Annual Report. Copenague: LEGO Company, 1999.

Savater, Fernando. El valor de educar. México: Instituto de Estudios Sindicales de América, 1997.

Valladolid, pp. $22-32$.

Vilches, Lorenzo. La migración digital. Barcelona: Gedisa, 2001.

Vigotsky, Lev. Mind in society. Harvard: Harvard, 1978. 